Georgia State University

ScholarWorks @ Georgia State University

$12-1-2009$

\title{
On the Coefficient of Variation as a Criterion for Decision under Risk
}

James Cox

Georgia State University

Vjollca Sadiraj

Georgia State University

Follow this and additional works at: https://scholarworks.gsu.edu/excen_workingpapers

\section{Recommended Citation}

Cox, James and Sadiraj, Vjollca, "On the Coefficient of Variation as a Criterion for Decision under Risk" (2009). ExCEN Working Papers. 80.

https://scholarworks.gsu.edu/excen_workingpapers/80

This Article is brought to you for free and open access by the Experimental Economics Center at ScholarWorks @ Georgia State University. It has been accepted for inclusion in ExCEN Working Papers by an authorized administrator of ScholarWorks @ Georgia State University. For more information, please contact scholarworks@gsu.edu. 


\title{
On the Coefficient of Variation as a Criterion for Decision under Risk
}

\author{
James C. Cox and Vjollca Sadiraj \\ Experimental Economics Center, Andrew Young School of Policy Studies, \\ Georgia State University
}

December 2009

Forthcoming in Journal of Mathematical Psychology 

25 supposition (with described options) similar to the one discussed by Rabin (2000); this is a 26

\section{On the Coefficient of Variation as a Criterion for Decision under Risk*}

Weber, Shafir, and Blais (2004) report a meta-analysis of data for animal and human decision making that uses the coefficient of variation (CV) as a measure of "risk sensitivity." They argue that CV, defined as the ratio of standard deviation (SD) to expected value (EV), is a good predictor of animal and human risk sensitivity. Weber et al. (2004, pgs. 432 - 434) review results from the analysis of animal data in Shafir (2000) in which the proportion of animals choosing certain (sure thing) rewards rather than risky rewards is regressed on the CV of risky rewards. For comparison, Weber, et al. (pg. 434) report results from another regression in which the proportion of sure thing choices is regressed on the EV of risky rewards. They conclude that: “...neither SD nor EV predicts risk sensitivity in isolation. Their ratio, however, in the form of the CV does so very well.”

Weber et al. (2004) report that a large advantage of CV over SD in fitting data occurred with data from environments in which decision makers had to learn about the outcome distribution of different options by trial and error sampling and personal experience. Arguably, such environments might better be described as involving uncertainty rather than risk (Knight, 1921). And different models of decision making might apply in environments characterized by uncertainty than in environments characterized by risk. Weber et al. (pg. 443), however, also offered their model as a solution to the implausibility problems for expected utility theory that follow from the concavity calibration critique that applies to theories of decision under risk (Rabin 2000). In response, we ask whether CV can provide either a credible normative criterion for decision making under risk or a useful descriptive model of decisions under risk in two experiments designed to test its distinctive properties. We also ask whether CV provides a useful descriptive model of decisions in an experiment designed to test a concavity calibration direct response to claims made about the CV model by Weber et al. 
Weber et al. (eq. 1, p. 433) write the utility of an option with random return $X$ as a linear

2 function of the utility of its expected value, $u(\operatorname{EV}(X))$ and its risk $\mathrm{R}(X)$. They note that, for a

3 quadratic utility function, the measure of risk is the variance, $\operatorname{Var}(X)$. They argue for use of the

4 dimension-invariant $\mathrm{CV}(X)$, instead of $\operatorname{Var}(X)$ or $\mathrm{SD}(X)$, as the measure of risk.

5 The CV measure only provides a measure of risk that is distinct from SD when it is

6 applied to distributions with distinct EVs. If application of CV were to be restricted to

7 comparisons across gambles with the same EV then it would produce a measure that was

8 identical to SD except for a scale factor. Thus we consider gambles with distinct EVs. Consider

9 two risky choice options with random returns, $X$ and $Y$. If for an individual $\mathrm{j}$ one has

$10 u_{j}(\mathrm{EV}(X))-b_{j} \mathrm{CV}(X)<u_{j}(\mathrm{EV}(Y))-b_{j} \mathrm{CV}(Y)$

11 then option $Y$ is more likely to be chosen than option $X$ by individual $j$ (Weber et al., pgs.

$12433,443)$.

13 We first ask whether choosing among risky alternatives according to the CV criterion (as

14 in statement (1)) would promote the self-interest of the decision maker. In other words, we ask

15 what are the normative properties of the CV criterion. Subsequently, we examine the descriptive

16 power of the CV measure of risk sensitivity in three experiments.

Normative properties of the CV Measure of Risk Sensitivity for Decision under Risk?

19 We here show that CV cannot provide a credible normative criterion for choosing between non-

20 degenerate lotteries because it is inconsistent with preference for more to less of the reward

21 medium (or "positive monotonicity" of preferences). Let a risk averse agent's choices over

22 lotteries that involve gains be characterized by some $b>0$ and some positively monotonic

23 function $u(\cdot)$ over expected payoffs, as in statement (1). Let positive numbers $\ell, k$, and $n>2$ be

24 given. Let $L_{n}$ denote the binary lottery that yields payoff of $\ell / p$ with probability $p$ and payoff 
1 of $n \ell /(1-p)$ with probability $1-p$. Similarly, $L_{n+k}$ denotes the binary lottery that yields

2 payoff of $\ell / p$ with probability $p$ and payoff of $(n+k) \ell /(1-p)$ with probability $1-p$.

3

4 Proposition 1. Let positive $\ell, k$, and $n>2$ be given. For all $\mathrm{b}>0$, there exists

$5 p \in[0.5,1)$ such that the individual is more likely to choose lottery $L_{n}$ than lottery $L_{n+k}$

6 according to the $\mathrm{CV}$ criterion.

$7 \quad$ Proof. See Appendix 1.

8

9 Note that the only difference between lotteries $L_{n}$ and $L_{n+k}$ is that the high outcome in

$10 L_{n+k}$ is larger than the high outcome in $L_{n}$ by the payoff amount $k \ell /(1-p)$. Yet lottery

$11 L_{n}$ is more likely to be chosen than $L_{n+k}$ according to the CV criterion. This is

12 inconsistent with positive monotonicity of preferences.

13 As an example, let $\ell=1, n=2$ and $k=1$. Suppose that an agent's coefficient $b$ in the

14 CV preference criterion (see statement (1)) is found to satisfy the inequality (*)

$15 b>6[u(4)-u(3)]$. Then application of Proposition 1 with $p=1 / 2$ implies that option $\mathrm{L}_{2}$ is

16 more likely to be chosen than option $L_{3}$ where: (a) option $L_{2}$ is the binary lottery that pays 2 or 4

17 with equal probabilities; and (b) option $L_{3}$ is the binary lottery that pays 2 or 6 with equal

18 probabilities. It can be easily verified that $E V_{L_{2}}=3, E V_{L_{3}}=4, C V_{L_{2}}=1 / 3$, and $C V_{L_{3}}=1 / 2$. So,

19 according to the CV measure of risk sensitivity,

$20 U\left(X_{L_{2}}\right)-U\left(X_{L_{3}}\right)=u(3)-b / 3-u(4)+b / 2>0$

21 where the last inequality follows from statement (*). Hence the CV criterion implies that the

22 agent is more likely to choose option $\mathrm{L}_{2}$ than option $\mathrm{L}_{3}$. But this conclusion is inconsistent with

23 the self-interest of any agent that is not satiated in the reward medium because the only difference 
1 between the two lotteries is that the high payoff equals 4 in option $L_{2}$ and 6 in option $L_{3}$. It is

2 easiest to think of these numbers as referring to amounts of money but that interpretation is not

3 necessary for our argument. If the payoffs are amounts of money then whether they are numbers

4 of dollars or millions of dollars or some other unit of account is irrelevant to the argument.

5 Another example (considered also in the next section) which illustrates the CV model's

6 inconsistency with positive monotonicity is as follows. Let option C be a sure payoff of 10.50 .

7 Option D pays 0 with probability $4 / 10$ and pays 22 with probability 6/10. The expected payoff in

8 option D is 13.2 whereas the $\mathrm{CV}$ of this option is 0.82 . Suppose that an agent weakly prefers

9 option C to option D. In that case, according to the CV criterion the agent has revealed that most

10 likely

$11 u(10.5) \geq u(13.2)-b \times 0.82$

12 Next consider options J and K. Option J pays 10 with probability 19/20 and pays 20 with

13 probability $1 / 20$ and has EV of 10.5 and CV of 0.21 . Option K pays 10 with probability $19 / 20$ and

14 pays 74 with probability $1 / 20$. It has EV of 13.2 and CV of 1.06 . Note however that inequality

15 (3) implies that

16

$$
\begin{aligned}
& u(E V(K))-b C V(K)=u(13.2)-b \times 1.06 \\
& <u(13.2)-b(0.82+0.21) \leq u(10.5)-b \times 0.21=u(E V(J))-b C V(J)
\end{aligned}
$$

17 Therefore, weak preference for option C over option D implies that option $\mathrm{J}$ is more likely to be

18 chosen than option K. But this is inconsistent with positive monotonicity of preferences because

19 the only difference between the two options is a high payoff of 20 in option $\mathrm{J}$ and 74 in option $\mathrm{K}$.

20 These examples demonstrate why CV cannot provide a credible normative criterion for

21 decision under risk because it implies in some contexts that agents prefer lower payoff to higher

22 payoff.

23

24

25 
Can CV Provide a Descriptive Model for Decision under Risk?

2 Although the CV criterion is inconsistent with positive monotonicity of payoff preferences,

3 perhaps it is nevertheless consistent with how agents actually make decisions. The literature that

4 reports experiments on decision under risk includes some reports of inconsistencies with first

5 order stochastic dominance, which is an implication of positive monotonicity. ${ }^{1}$ And some of these

6 experiments involve real decisions among risky alternatives with non-trivial salient money

7 payoffs rather than reports of hypothetical preferences. ${ }^{2}$ Previous experiments do not provide

8 support for the type of transparent violation of payoff (or consequence) monotoncity

9 demonstrated above for the CV criterion. But they were not designed to test the specific

10 implications of the CV criterion. Experiment 1 provides such a test.

\section{Experiment 1}

13 Consider again the second example of properties of the CV criterion in the preceding section. The

14 reasoning takes the form: (a) if an agent weakly prefers option $\mathrm{C}$ to option $\mathrm{D}$ then (b) the CV

15 model implies that the agent is more likely to choose option $\mathrm{J}$ than option $\mathrm{K}$, between which the

16 only difference is a $1 / 20$ probability of getting 20 in option $\mathrm{J}$ and 74 in option $\mathrm{K}$. But what if

17 almost no one were to actually prefer option $\mathrm{C}$ to option $\mathrm{D}$ ? If that were the case, then the

18 example might not be compelling. We here report an experiment with these four options. In the

19 experiment, the payoff numbers represent amounts of money in 2009 U.S. dollars.

20 Subjects were informed that the experiment included two decision tasks and that a coin

21 would be flipped to determine which task paid money. Subjects were first shown options C and D

22 and asked to choose one option, by circling C or D, or to record indifference ("I don't care”) by

23 circling I. Subjects were told that if they circled I then the experimenter would choose option A or

24 option B for them. After making their decisions about options C and D, subjects were shown

25 options $\mathrm{J}$ and $\mathrm{K}$ and asked to choose one option or record indifference. 
Before making any decisions, subjects were invited to inspect the coin that would be

2 flipped to select which decision would be paid. They were shown the box containing four white

3 balls and six red balls that would be used to determine payoffs in option D. Before making their

4 option $\mathrm{J}$ and $\mathrm{K}$ decisions, subjects were shown the box containing 19 white balls and one orange

5 ball that would be used to determine payoffs for options J and K. They were informed that, after

6 making their choices, they would be called one at a time to observe the coin flip that would select

7 one of their two decision pages for payoff and that they would themselves each draw one ball

8 from the appropriate box (except for an option C choice). They were informed that they would be

9 invited to inspect the coin and the contents of a box immediately before these "urns" were used to

10 determine an individual's payoff. Subject instructions and decision pages (or response forms) for

11 experiment 1 are included in the appendix.

12 Experiment 1 included 66 volunteer subjects who were students at Georgia State

13 University. 37 of the subjects chose option $C$ and one chose indifference between options $C$ and

14 D. Recall that the CV criterion predicts that all of these 38 subjects will more likely choose

15 option $\mathrm{J}$ than option $\mathrm{K}$, so the majority of them should be observed to choose option J. Data

16 reject this hypothesis. All of these 38 subjects chose option K rather than option J. (In fact, all 66

17 subjects in the experiment chose option K.) Therefore, the CV model does not provide an

18 empirically valid descriptive model for decisions by subjects in this experiment. In contrast,

19 theories of decision under risk such as expected utility theory, dual theory of expected utility

20 (Yaari, 1987), and rank dependent expected utility theory (Quiggin, 1993), are consistent with

21 data for all of the subjects in this experiment. These theories predict that all agents will more

22 likely choose option K rather than option J, regardless of whether they choose option C or option

$23 \mathrm{D}$, because the theories incorporate positive monotonicity of preferences in the reward medium. 
2 In experiment 2 subjects were asked to choose between two options or record indifference on

3 each of six decision pages. One of the six decision pages of each subject was randomly chosen for

4 money payoff by rolling a die in the presence of the subject. Experiment 2 instructions and

5 decision pages (or response forms) are included in the appendix. The decision pages were given

6 to each subject in an independently drawn random order. Subjects had access to all six decision

7 pages while making each decision.

8 Before making their decisions, subjects were invited to inspect the die that would be

9 rolled to select which decision would be paid. They were shown the bingo cage containing balls

10 numbered $1,2, \ldots, 10$ that would be used to determine lottery payoffs. They were informed that,

11 after making their choices, they would be called one at a time to observe the die roll that would

12 select one of their six decision pages for payoff and that they would observe selection of a ball

13 from the bingo cage if they had chosen the lottery on the selected decision page. They were

14 informed that they would be invited to inspect the die and the contents of the bingo cage

15 immediately before these "urns" were used to determine an individual's payoff.

16 Table 1 reports the six decision tasks in experiment 2 that were presented to the subjects

17 in lettered tables, one table to a page. Each decision table contained the two options in a single

18 row of Table 1. In the "Table Q" decision task, for example, a subject is asked to choose between

$19 \$ 7$ for sure and the binary lottery that pays $\$ 2.50$ if ball 1 is drawn from the bingo cage or pays

$20 \$ 7.50$ if ball 2, 3,..,9, or 10 is drawn. Table 1 reports the EV and CV of option B in each of six

21 decision tables. (The subjects were not given the EV and CV values.) Note that the EV of option

22 B in each table equals the sure payoff in option $\mathrm{A}$ of that table. The CV measure increases

23 monotonically with decision table, from a low of 0.21 for Table Q to a high of 2.50 for Table T.

24 Therefore, if the CV measure is consistent with subjects' decision making under risk then their

25 frequency of choosing the sure amount of payoff should be correlated with the CVs of options B

26 in these tables since 


$$
u(E V(A))-b C V_{A}-u(E V(B))+b C V_{B}=b C V_{B}
$$

\section{$3 \quad$ Data from Experiment 2}

4 Different subjects participated in experiment 2 than in experiment 1. Experiment 2 included 50

5 volunteer subjects who were students at Georgia State University. Figure 1 shows graphs of the

6 proportions of subjects who chose the safe option and the CVs of the lotteries in six tables in the

7 experiment. The proportion of subjects who chose the sure thing shows no clear relationship to

8 the CVs of options B in different tables. The rank correlation coefficient is 0.143 . The Spearman

9 test reports a p-value of 0.787 , so the null hypothesis that proportions of choices of the sure thing

10 and CVs of the risky lotteries are independent is not rejected. We also ran a linear regression of

11 the observed proportions of choices of the sure options on the CVs of the paired risky options.

12 The OLS-estimated coefficient for the CV variable is 0.043 (p-value is 0.591 ) and the constant is

130.632 (p-value is 0.004 ). So again, the CV model has no explanatory power for these data as

14 revealed by the p-value of 0.591 .

15 The Spearman test, the graphs in Figure 1, and the linear regression use aggregate data.

16 Perhaps the effects of subject heterogeneity mask the effects of CV on individuals' willingness to

17 take risks. To address this question, we ran logit and probit regressions on individual data. The

18 Linear CV column of Table 2 for experiment 2 data reports estimates from a clustering logit

19 analysis of the data in which observations for each individual subject comprise a "group" of

20 observations. $^{3}$ The explanatory variables are CV of the risky lotteries and a constant. The

21 estimated parameter $\hat{b}$ of the coefficient on $\mathrm{CV}$ is not significantly different from 0 . Hence,

22 according to the logit analysis of data, CV has no explanatory value for individual subjects'

23 choices in experiment 2. Probit estimation leads to the same conclusion.

24 Perhaps subject heterogeneity, that cannot be captured by the individual-specific error

25 terms in clustered data analysis, masks the explanatory power of $\mathrm{CV}$ in the results reported in 
1 Table 2. We next ask whether adding questionnaire data to the econometric model changes the

2 conclusions about the insignificance of CV. We conducted logit and probit (with individual

3 subjects' clusters) analyses of data using CV and 15 measures of subjects' individual

4 characteristics as right-hand variables that are additive to CV. These 15 measures are provided by

5 subjects' responses to the questionnaire included in the appendix. In these data analyses,

6 coefficients on some of the subject-characteristic variables (such as age, “opportunity seeking,"

7 and "get jittery”) are significant but coefficients on CV are not; the estimated values of $\hat{b}$ and

8 their p-values (in parentheses) are 0.152 and (0.137) for probit and 0.240 and $(0.180)$ for logit.

9 We also conducted probit and logit analyses in which subjects' coefficients for CV are estimated

10 as a function of the subject characteristic variables (using the approach in Harrison and Rutstrom,

11 2008). Again, logit and probit analyses do not detect a significant effect of the CV of risky

12 lotteries on subjects' choices.

13

\section{Application of An Alternative Model}

15 A natural question to ask is whether an alternative theory of decision under risk can rationalize

16 data from experiment 2. A more pointed question is whether an alternative theory that

17 incorporates positive monotonicity can rationalize the data. We apply rank dependent theory of

18 decision under risk to the data. For lotteries in which all payoffs are positive, the income model

19 of rank dependent expected utility theory (Quiggin, 1993) and cumulative prospect theory

20 (Tversky and Kahneman, 1992) are equivalent; hence we label this income model simply as RD,

21 for "rank dependent." For binary lotteries, this RD utility functional can be written in a simple

22 form, as follows. Consider two binary lotteries, $\mathrm{X}$ and $\mathrm{Y}$. Lottery $\mathrm{X}$ has probability $p_{X}$ of the

23 larger payoff $x_{L}$ and probability $1-p_{X}$ of the smaller payoff $x_{S}$. Lottery Y has probability $p_{Y}$

24 of the larger payoff $y_{L}$ and probability $1-p_{Y}$ of the smaller payoff $y_{S}$. The probability 
1 transformation function for agent $j$ is $h_{j}(\cdot)$ and the utility of payoff function is $u_{j}(\cdot)$. With RD

2 theory, lottery $\mathrm{X}$ is preferred to lottery $\mathrm{Y}$ by agent $j$ if ${ }^{4}$

$3 \quad h_{j}\left(p_{X}\right) u_{j}\left(x_{L}\right)+\left[1-h_{j}\left(p_{X}\right)\right] u_{j}\left(x_{S}\right)>h_{j}\left(p_{Y}\right) u_{j}\left(y_{L}\right)+\left[1-h_{j}\left(p_{Y}\right)\right] u_{j}\left(y_{S}\right)$

4 We follow common practice in applications of RD theory to data by using a parametric 5 model with probability transformation and utility of payoff functions given by $6 \quad h_{j}(p)=w(p)=p^{\theta} /\left(p^{\theta}+(1-p)^{\theta}\right)^{1 / \theta}$ and $u_{j}(x)=x^{r}$, for all $j$ (Tversky and Kahneman, 7 1992) . Option A in each pair of options in experiment 2 is a sure thing (or "degenerate lottery”)

8 with payoff $x_{A}$. Hence with the parametric RD model, option A is preferred to risky option B by 9 agent $j$ if

$$
\Delta U_{j}^{R D}=\left[\left(x_{A}\right)^{r_{j}}-\left(x_{S}\right)^{r_{j}}\right]-w\left(p_{B}\right)\left[\left(x_{L}\right)^{r_{j}}-\left(x_{S}\right)^{r_{j}}\right]>0
$$

11 The above inequality and the nature of payoffs and probabilities chosen in our 12 experiment imply the following hypothesis with respect to the explanatory power of the RD 13 model. First, it can be verified straightforwardly that if the estimated $\hat{r}$ is not significantly 14 different from 0 then this model has no explanatory power. Second, recall that a characteristic of 15 our experimental design is that $x_{A}-x_{S}=p_{B}\left(x_{L}-x_{S}\right)$. Therefore, if the estimated $\hat{\theta}$ is not 16 significantly different from 1 and the estimated $\hat{r}$ is also not significantly different from 1 then 17 the RD model has no explanatory power. Logit analysis of data from experiment 2 with the RD 18 model is reported in the RD Model column of Table 2. Estimates of $\hat{\theta}$ and $\hat{r}$ are significantly 19 different from 0 (with p-values $=0.000$ ). We report chi-square tests for nonlinearity of the 20 probability transformation and utility of payoff functions. The hypothesis that $\hat{\theta}=1$ is rejected

21 (p-value is 0.008). The joint hypothesis that $\hat{\theta}=1$ and $\hat{r}=1$ is also rejected (p-value is 0.000 ).

22 Therefore data from experiment 2 can be rationalized by the RD model. Probit estimation leads to 23 the same conclusions. 


\section{Implications of Data from a Concavity Calibration Experiment}

3 Experiments 1 and 2 were designed to test distinguishing features of the CV model. Referees

4 have suggested that such tests can be viewed as ones “designed to make the theory fail." Perhaps

5 so, but this is a common characteristic of tests of other theories of decision under risk. For

6 example, tests for Allais paradox and related phenomena are important precisely because they are

7 designed to test implications of the most central distinguishing characteristic of expected utility

8 theory, the independence axiom. But it is nevertheless an interesting question to ask whether data

9 from experiments designed to test other decision theories have implications for the CV model.

10 We here use data from an experiment designed to test a version of Rabin's (2000) calibration

11 proposition. This seems especially appropriate since Weber et al. (pg. 443) offered their model as

12 an alternative to models called into question by this calibration proposition.

13 Cox et al. (2009) reports data from experiments designed to test the small-stakes risk

14 aversion suppositions in calibration propositions for several prominent theories that represent risk

15 aversion with nonlinear transformation of payoffs or nonlinear transformation of probabilities (or

16 both). One of those experiments, designed to test the version of the concavity calibration

17 proposition reported in Cox and Sadiraj (2006), uses the following choice options. Subjects

18 choose between a certain amount $x$ and a 50/50 lottery that pays $x-100$ or $x+110$ for each

19 value of $x$ in $\{3 \mathrm{~K}, 9 \mathrm{~K}, 50 \mathrm{~K}, 70 \mathrm{~K}, 90 \mathrm{~K}, 110 \mathrm{~K}\}$, where $\mathrm{K}=1,000$. In this experiment, money

20 payoffs were in "contingent euros," which were received only with low probability if a

21 subsequent casino bet by the experimenter paid off..$^{5}$ The CV criterion says that option B is more

22 likely to be chosen than option A if

$$
\mathrm{u}(\mathrm{EV}(\mathrm{B}))-\mathrm{u}(\mathrm{EV}(\mathrm{A}))-\mathrm{b}[\mathrm{CV}(\mathrm{B})-\mathrm{CV}(\mathrm{A})]>0
$$

24 Let option B denote the certain payoff $x$. Let option A denote the 50/50 lottery. The expected

25 value of option A is $x+5$ whereas the expected value of option B is of course $x$. Hence, the 
1 expected value of option A is always larger than the expected value of option $\mathrm{B}$, for all positive $2 x$.

3 The CVs of option A and option B are, respectively, 105/ $(x+5)$ and 0. Clearly, option

4 A's CV is decreasing in $x$, hence so is the likelihood of choosing option B according to the CV

5 criterion. The data are inconsistent with this. We observed mostly non-decreasing proportions

$6(0.41,0.40,0.48,0.50,0.54,0.53)$ of option B choices as $x$ varied from 3,000 to 110,000 .

7 Figure 2 shows values of $\mathrm{CV}$ and proportions of option B (the certain payoff option) across

8 choice pairs. We also ran OLS and nonlinear regressions of the observed proportions of option B

9 choices on CV(A) and the scaled certain amounts of payoff $z=x / 10,000$. The OLS-estimated

10 coefficient for the CV variable is -3.36 and it is marginally significantly different from 0 (p-value

$11=0.075)$ but its sign is the opposite of the one predicted by the CV criterion for risky choices on

12 the gain domain.

13 We analyzed data at the individual level using logit amd probit estimators for the CV

14 model. The empirical specification comes from the power function form, $u(E V)=E V^{r}$, which

15 implies

16

$$
\Delta U^{C V}=x^{r}-(x+5)^{r}+b C V(x)
$$

17 We call this the Nonlinear CV Model. Recall that in our experiment $x$ takes values from $18\{3 \mathrm{~K}, 9 \mathrm{~K}, 50 \mathrm{~K}, 70 \mathrm{~K}, 90 \mathrm{~K}, 110 \mathrm{~K}\}$, where $\mathrm{K}=1,000$, whereas the difference in expected value 19 of the binary lottery and the sure amount of money is simply 5. For comparison with 20 other estimations, we also estimated the linear specification of the CV model used above 21 and in Weber, et al. (2004), that is $\Delta U^{C V}=b C V(x)$. The Linear CV Model and

22 Nonlinear CV Model columns of Table 2 for data from the concavity calibration experiment

23 report estimates of $\hat{b}$ that are negative and insignificant whereas the CV model implies that they 
1 should be significantly positive. We conclude that the CV criterion has no explanatory value for

2 data from the concavity calibration experiment.

3 For the RD model, the specification comes from power functions $u(y)=y^{r}$ for payoffs

4 and $w(p)=p^{\theta} /\left(p^{\theta}+(1-p)^{\theta}\right)^{1 / \theta}$ for probabilities, which implies

$5 \quad \Delta U^{R D}=x^{r}-w(0.5)(x+110)^{r}-(1-w(0.5))(x-100)^{r}$

6 The RD Model column of Table 2 reports significantly positive estimates of $\hat{\theta}$ and $\hat{r}$, as implied

7 by $\mathrm{RD}$ theory. We conclude that the $\mathrm{RD}$ model can rationalize data from the calibration

8 experiment whereas the CV model cannot.

\section{Conclusion}

11 We conclude that the CV criterion does not provide a credible normative criterion for decision

12 under risk because it is inconsistent with positive monotonicity of preferences for payoffs. The

13 CV criterion does not provide a useful descriptive model of subjects' decision making in the risky

14 environment of experiments 1 and 2 designed to test the criterion's distinctive properties. In

15 contrast rank dependent theory of decision under risk, that incorporates positive monotonicity of

16 preferences for payoffs, is consistent with data from experiments 1 and 2. Finally, the CV

17 criterion does not provide a useful descriptive model for subjects' decisions in an experiment

18 designed to test a supposition used in concavity calibration propositions for prominent theories of

19 decision under risk. This last test is a direct response to the claim that the CV criterion provides a

20 solution to the problems for plausibility of theories of decision under risk that arise from the

21 concavity calibration critique. 


\section{Endnotes}

1 * We wish to thank Jerome R. Busemeyer, Michael Lee, and anonymous reviewers for helpful

2 comments and suggestions on earlier versions. The National Science Foundation provided

3 support for this research (grant numbers IIS-0630805 and SES-0849590).

4 1. Let $F$ and $G$ be two cumulative probability distributions of payoffs defined on the set $\Omega$.

5 Strict first order stochastic dominance of $F$ over $G$ (Hadar \& Russell, 1969; Rothschild \&

6 Stiglitz, 1970) is defined by:

7 (i) $F(x) \leq G(x)$, for all $x \in \Omega$; and (ii) $F\left(x_{k}\right)<G\left(x_{k}\right)$, for at least one $x_{k} \in \Omega$.

8 2. See, for example, Loomes, Starmer, and Sugden (1992).

9 3. Stata software for logit analysis does not use the seven observations in which subjects chose

10 indifference rather than strict preference for option A or option B (coded as 0 and 1). Hence the

11 parameter estimates are based on 293 observations.

12 4. The original exposition of rank dependent expected utility theory (Quiggin, 1993) orders

13 payoffs from lowest to highest. We here follow recent convention that orders payoffs from

14 highest to lowest for both that theory and other rank dependent theories such as cumulative

15 prospect theory.

16 5. The experiment design and contingent payoff protocol are discussed in greater detail in Cox et

17 al. (2009). The six other experiments reported in that paper use ordinary money payoffs rather

18 than contingent payoffs. 


\section{References}

2 Cox, J. C. \& Sadiraj, V. (2006). Small- and large-stakes risk aversion: Implications of concavity

3 calibration for decision theory. Games and Economic Behavior, 56, 45-60.

4 Cox, J. C., Sadiraj, V., Vogt, B., \& Dasgupta, U. (2009). Is there a plausible theory for decision

5 under risk? Experimental Economics Center working paper, Georgia State University.

6 Hadar, J. \& Russell, W. R. (1969). Rules for ordering uncertain prospects. American Economic

$7 \quad$ Review, 59, 25-34.

8 Harrison, G.W. \& Rutstrom, E.E. (2008). Risk aversion in the laboratory. In: J. C. Cox and G.

9 W. Harrison (Eds.) Risk aversion in experiments (Vol.12). Bingley, UK: Emerald, Research in

10 Experimental Economics, 41-196.

11 Knight, F. H. (1921). Risk, uncertainty, and profit. Boston: Houghton.

12 Loomes, G., Starmer, C. \& Sudgen R. (1992). Are preferences monotonic: Testing some

13 implications of regret theory. Economica, 59, 17-33.

14 Quiggin, J. (1993). Generalized expected utility theory: The rank-dependent model. Boston:

15 Kluwer.

16 Rabin, M. (2000). Risk aversion and expected utility theory: A calibration theorem.

$17 \quad$ Econometrica, 68, 1281-1292.

18 Rothschild, M. \& Stiglitz, J.E. (1970). Increasing risk: I. A definition. Journal of Economic

19 Theory, 2, 225-243.

20 Shafir, S. (2000). Risk-sensitive foraging: The effect of relative variability. Oikos, 88, 663-669.

21 Tversy, A. \& Kahneman, D. (1992). Advances in prospect theory: Cumulative representation of

22 uncertainty. Journal of Risk and Uncertainty, 5, 297-323.

23 Weber, E. U., Shafir, S., \& Blais, A. (2004). Predicting risk sensitivity in humans and lower

24 animals: Risk as variance or coefficient of variation. Psychological Review, 111, 430-445.

25 Yaari, M. E. (1987). The dual theory of choice under risk. Econometrica, 55, 95-115. 
Table 1. Options A and B in Six Decision Pages in Experiment 2

\begin{tabular}{|c|c|c|c|c|c|c|c|}
\hline \multirow{2}{*}{ Table } & \multirow{2}{*}{ Option A } & \multicolumn{5}{|c|}{ Option B } \\
\hline & & Low Payoff $\$$ & Low Payoff Balls & High Payoff $\$$ & High Payoff Balls & EV & CV \\
\hline $\mathrm{Q}$ & $\$ 7$ & $\$ 2.50$ & 1 & $\$ 7.50$ & $2,3,4,5,6,7,8,9,10$ & $\$ 7$ & 0.21 \\
\hline $\mathrm{S}$ & $\$ 27$ & $\$ 2.50$ & $1,2,3$ & $\$ 37.50$ & $4,5,6,7,8,9,10$ & $\$ 27$ & 0.59 \\
\hline $\mathrm{U}$ & $\$ 35$ & $\$ 2.50$ & $1,2,3,4,5$ & $\$ 67.50$ & $6,7,8,9,10$ & $\$ 35$ & 0.93 \\
\hline $\mathrm{W}$ & $\$ 31$ & $\$ 2.50$ & $1,2,3,4,5,6,7$ & $\$ 97.50$ & $8,9,10$ & $\$ 31$ & 1.40 \\
\hline $\mathrm{R}$ & $\$ 22$ & $\$ 2.50$ & $1,2,3,4,5,6,7,8$ & $\$ 100.00$ & 9,10 & $\$ 22$ & 1.77 \\
\hline $\mathrm{T}$ & $\$ 15$ & $\$ 2.50$ & $1,2,3,4,5,6,7,8,9$ & $\$ 127.50$ & 10 & $\$ 15$ & 2.50 \\
\hline
\end{tabular}


Table 2. Logit Analysis of Data

\begin{tabular}{|c|c|c|c|c|c|}
\hline \multirow[b]{2}{*}{$\begin{array}{c}\text { Parameter Estimates } \\
\text { and Statistics }\end{array}$} & \multicolumn{2}{|c|}{ Experiment 2} & \multicolumn{3}{|c|}{ Concavity Calibration Experiment } \\
\hline & Linear CV Model & RD Model & Linear CV Model & Nonlinear CV Model & RD Model \\
\hline$\hat{b}$ & $\begin{array}{l}0.198 \\
(0.211)\end{array}$ & & $\begin{array}{r}-12.639 \\
(0.354)\end{array}$ & $\begin{array}{l}-9.381 \\
(0.562)\end{array}$ & \\
\hline$\hat{\theta}$ & & $\begin{array}{l}0.739 * * * \\
(0.000)\end{array}$ & & & $\begin{array}{l}1^{* * *} \\
(0.000)\end{array}$ \\
\hline$\hat{r}$ & & $\begin{array}{l}0.428 * * * \\
(0.000)\end{array}$ & & $\begin{array}{l}0.581 \\
(0.286)\end{array}$ & $\begin{array}{l}0.686^{* * *} \\
(0.000)\end{array}$ \\
\hline constant & $\begin{array}{r}0.557 * * \\
(0.008)\end{array}$ & & $\begin{array}{l}0.011 \\
(0.969)\end{array}$ & & \\
\hline Log-likelihood & -180.83 & -182.55 & -166.72 & -166.70 & -166.93 \\
\hline $\begin{array}{c}\text { Chi-square test } \\
\text { of } \theta=1\end{array}$ & & $\begin{array}{l}6.97 * * \\
(0.008) \\
\end{array}$ & & & $\begin{array}{c}0.00 \\
(0.999) \\
\end{array}$ \\
\hline $\begin{array}{c}\text { Chi-square test } \\
\text { of } r=1 \\
\end{array}$ & & $\begin{array}{c}60.88^{* * * *} \\
(0.000)\end{array}$ & & $\begin{array}{c}0.59 \\
(0.442)\end{array}$ & $\begin{array}{l}7.64 * * \\
(0.006)\end{array}$ \\
\hline $\begin{array}{c}\text { Chi-square test of } \\
\theta=1 \text { and } r=1\end{array}$ & & $\begin{array}{c}67.41 * * * \\
(0.000) \\
\end{array}$ & & & \\
\hline Nr of observations & 293 & 293 & 242 & 242 & 242 \\
\hline
\end{tabular}

Linear CV Model: $\operatorname{Pr}($ sure $)=F(b C V+c)$. Nonlinear CV Model: $\operatorname{Pr}($ sure $)=F\left(\right.$ sure $\left.^{r}-E V^{r}+b C V\right)$. RD Model:

$\operatorname{Pr}($ sure $)=F\left(\right.$ sure $\left.^{r}-L^{r}-w(p)\left(H^{r}-L^{r}\right)\right)$. p-values are reported in brackets. Linear CV Model columns report estimates using standard STATA (probit command, cluster(id)). Other columcontain estimates as in the Harrison approach since STATA does not contain code for these models. ${ }^{*}$ denotes $\mathrm{p}$-value $<0.05 .{ }^{* *}$ denotes $\mathrm{p}$-value $<0.01 .{ }^{* * *}$ denotes $\mathrm{p}$-value $<0.001$ 
1

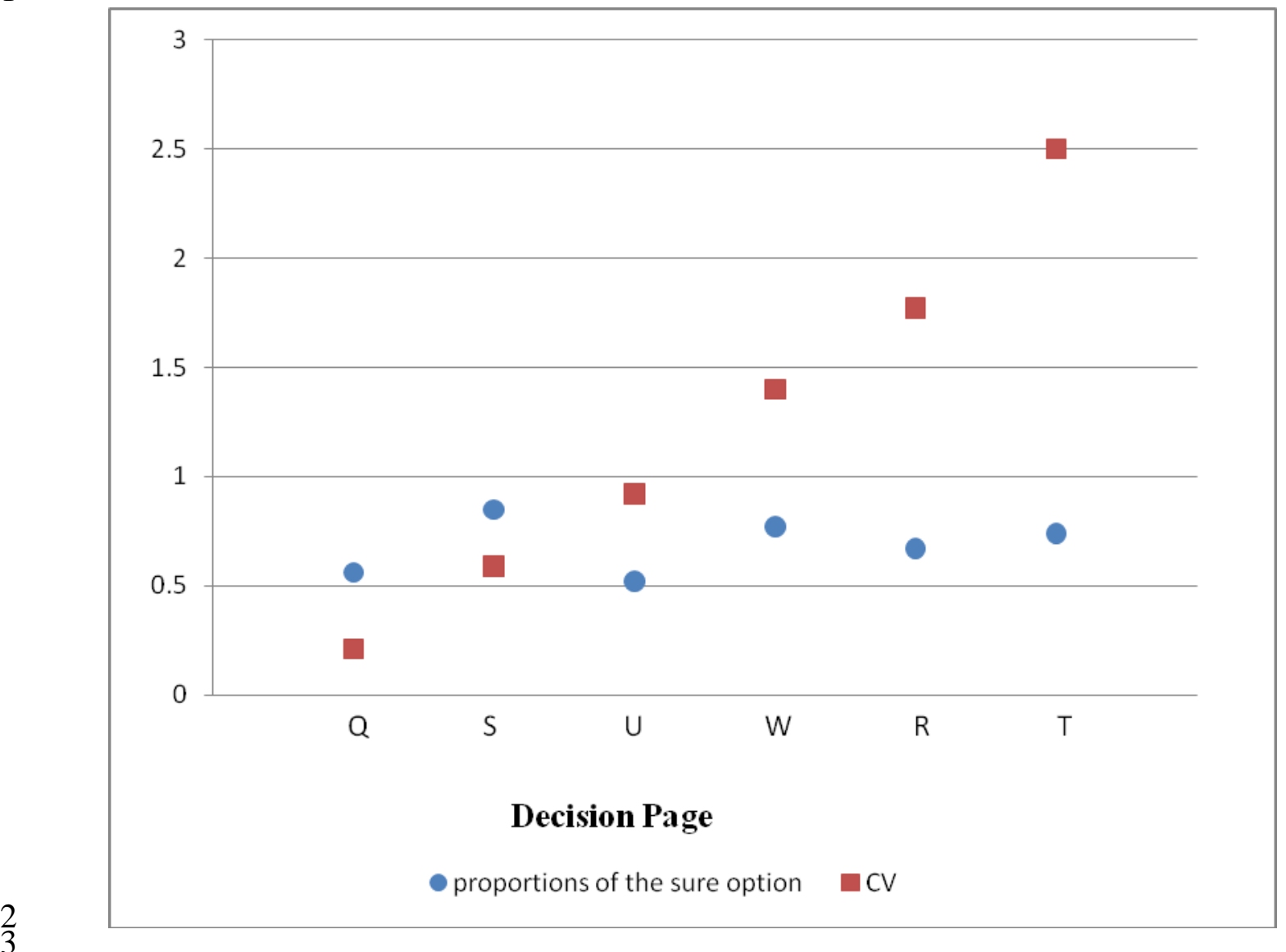

Figure 1. Choices of the Sure Option and Values of CV in Experiment 2 
1

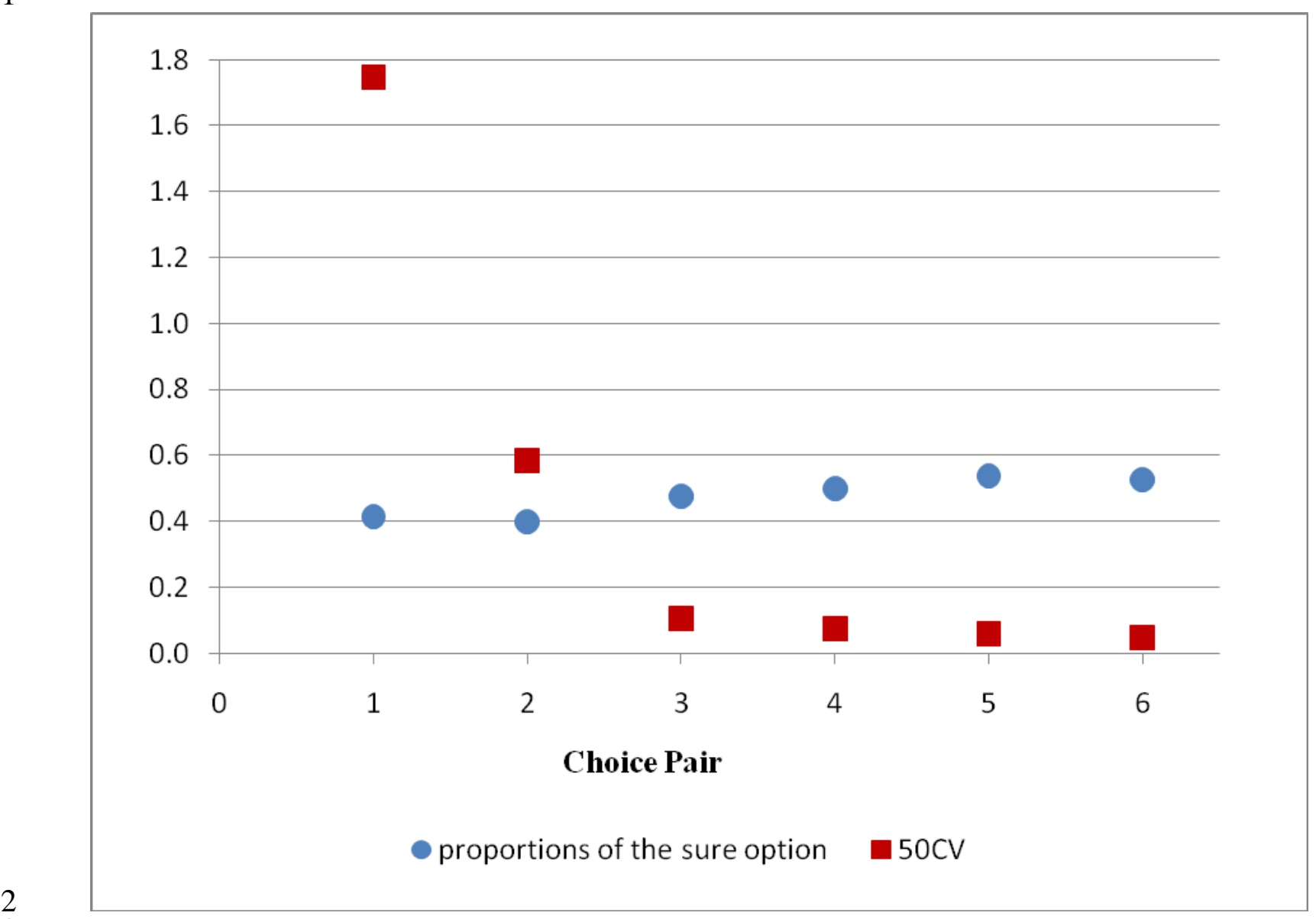

3

4

5

Figure 2. Choices of the Sure Option and Values of CV in the Calibration Experiment 
and

$$
C V=\sqrt{\frac{\ell^{2} / p+n^{2} \ell^{2} /(1-p)}{(n+1)^{2} \ell^{2}}-1}=\frac{|p-1 /(n+1)|}{\sqrt{p(1-p)}}
$$

It can be easily checked that for $p>1 /(n+1)$, which follows from $p \in[0.5,1)$, and $n>2$, the $\mathrm{CV}$ of gambles $L_{n}$ is increasing in $n$. According to the CV measure of risk sensitivity (Weber et al., pgs. 433, 443), probability of choosing $L_{n}$ is

$$
\left.\operatorname{Pr}\left(L_{n}\right)=F\left(u\left(E V_{L_{n}}\right)-b C V_{L_{n}}-u\left(E V_{L_{n+k}}\right)+b C V_{L_{n+k}}\right)\right)
$$

where $F: R->[0,1]$, increasing and $\mathrm{F}(0)=0.5$. Substituting expressions for EV and CV yields

$$
u\left(E V_{\mathrm{L}_{\mathrm{n}}}\right)-b C V_{\mathrm{L}_{\mathrm{n}}}=u((n+1) \ell)-b \frac{|p-1 /(n+1)|}{\sqrt{p(1-p)}}
$$

$$
u\left(E V_{\mathrm{L}_{\mathrm{n}+\mathrm{k}}}\right)-b C V_{\mathrm{L}_{\mathrm{n}+\mathrm{k}}}=u((n+1+k) \ell)-b \frac{|p-1 /(n+1+k)|}{\sqrt{p(1-p)}}
$$

Therefore, in statement (a.2), we get that

$$
\operatorname{Pr}\left(L_{n}\right)=F\left(u((n+1) \ell)-u((n+1+k) \ell)-b\left[C V_{L_{n}}-C V_{L_{n+k}}\right]\right)
$$

$$
=F\left(-\Delta u+\frac{b}{\sqrt{p(1-p)}} \frac{k}{(n+k+1)(n+1)}\right)
$$

that

$22 \operatorname{Pr}\left(L_{n}\right)>1 / 2$ if the expression on the right-hand-side of (a.5) is positive, which is equivalent 23 with

$$
\frac{b k}{(n+1)(n+1+k) \Delta u} \geq \sqrt{p(1-p)}
$$

For any given $n, k, u($.$) , and b$, the left hand side of the last inequality (a.6) is a finite number, say C. The right-hand side has limit 0 for $p$ close to 1 . So, we can always find a $p$ such that 


\section{Appendix 2. Subject Instructions and Decision Pages for Experiment 1}

\section{Subject Instructions}

No Talking: Now that the experiment has begun, we ask that you do not talk. If you have a question, please raise your hand and the experimenter will approach you and answer your question in private.

Money Payoff: You will be paid an amount determined by your decisions in this experiment and the outcomes from flipping a coin and picking a colored ball from a box.

The experiment proceeds as follows. First, you choose your preferred option in each of two tables. Second, which of the two tables will be selected for money payoff will be determined by flipping a coin. The side of the coin that lands up determines which one of your decision tables pays money.

Note that only one of your two decisions will be selected for money payoff by flipping a coin; thus you should decide which option you prefer in each table independently of your choice in the other table.

\section{Heads Choice Page}

If the coin lands heads then you will be paid for your choice in Table 1. Please decide whether you prefer Option A or Option B. If you don't care which option you get, then you can choose Option I (which stands for “I don’t care”).

In Table 1, if you choose Option A, then your payoff is $\mathbf{\$ 1 0 . 5 0}$ (if Table 1 is selected by coin flip).

If you choose Option B (and Table 1 is selected by coin flip) then your payoff is determined by picking a ball from a box that contains $\mathbf{4}$ white balls and $\mathbf{6}$ red balls. Your payoff from choosing Option B is:

$\$ 0$ if you pick one of the 4 white balls;

$\$ 22$ if you pick one of the 6 red balls.

Please mark your choice by circling A, B, or I in the My Choice column.

Table 1

\begin{tabular}{|c|c|c|}
\hline Option A & Option $\mathbf{B}$ & My Choice \\
\hline \multirow{2}{*}{$\mathbf{\$ 1 0 . 5 0}$} & $\mathbf{\$ 0}$ if you draw one of the $\mathbf{4}$ white balls & or \\
& $\mathbf{\$ 2 2}$ if you draw one of the $\mathbf{6}$ red balls & B I \\
\hline
\end{tabular}


1

\section{$\underline{\text { Tails Choice Page }}$}

If the coin lands tails then you will be paid for your choice in Table 2. Please decide whether you prefer Option X or Option Y. If you don’t care which option you get, then you can choose Option I (which stands for “I don’t care”).

If you choose Option X (and Table 2 is selected by coin flip) then your payoff is determined by picking a ball from a box that contains 1 orange ball and 19 white balls. Your payoff from choosing Option $\mathrm{X}$ is:

$\$ 10$ if you pick one of the 19 white balls;

$\$ 20$ if you pick the 1 orange ball.

If you choose Option Y (and Table 2 is selected by coin flip) then your payoff is determined by picking a ball from a box that contains 1 orange ball and 19 white balls. Your payoff from choosing Option Y is:

$\$ 10$ if you pick one of the 19 white balls;

$\$ 74$ if you pick the 1 orange ball.

Please mark your choice by circling X, Y, or I in the My Choice column.

\section{Table 2}

\begin{tabular}{|c|c|c|}
\hline Option $\mathbf{X}$ & Option $\mathbf{Y}$ & My Choice \\
\hline $\begin{array}{l}\mathbf{\$ 1 0} \text { if you pick one of the } \mathbf{1 9} \text { white balls } \\
\text { or } \\
\mathbf{\$ 2 0} \text { if you pick the } \mathbf{1} \text { orange ball }\end{array}$ & $\begin{array}{l}\$ 10 \text { if you pick one of the } 19 \text { white balls } \\
\text { or } \\
\$ 74 \text { if you pick the } 1 \text { orange ball }\end{array}$ & $\begin{array}{lll}\mathbf{X} & \mathbf{Y} & \mathbf{I}\end{array}$ \\
\hline
\end{tabular}


Appendix 3: Subject Instructions, Decision Pages, and Questionnaire for Experiment 2

$4 \quad$ Subject Instructions

6 You will be paid an amount determined by your decisions in this experiment and the outcomes

7 from rolling a die and drawing a numbered ball from a bingo cage.

9 The experiment proceeds as follows. First, you choose your preferred option in each of six 10 tables. Second, which of the six tables will be selected for money payoff will be determined by 11 rolling a six-sided die in your presence. The number that ends "up" on the die determines which 12 one of your decision tables pays money.

14 Note that only one of your six decisions will be selected for money payoff by rolling the die; thus 15 you should decide which option you prefer in each table independently of your choice in other 16 tables.

You are asked to choose either option A or option B in each of six tables.

The example below shows the type of choice table that will be included in the experiment.

22 In Table 1, if you choose Option A, then your payoff is \$54 (if this table is selected by rolling the 23 die).

If you choose Option B (and this table is selected by rolling the die) then your payoff is 26 determined by drawing a ball from a bingo cage that contains 10 balls with 10 different numbers.

27 Your payoff from choosing Option B is:

$28 \quad \$ 5$ if the bingo cage selects ball 1, 2, or 3;

You indicate your choice in the third column. If you prefer Option A to Option B then circle A. If

32 you prefer Option B to Option A then circle B. In case you are indifferent between the two 33 options, you circle I. If I is circled then the experimenter will choose Option A or Option B for 34 you. 
Table 1

\begin{tabular}{|l|c|c|}
\hline Option A & Option B & My Choice \\
\hline \multirow{2}{*}{$\$ 54$} & \$5 if ball from $\{\mathbf{1}, \mathbf{2 , 3}\}$ & A $\quad$ B I \\
& $\$ 75$ if ball from $\{4,5, \mathbf{6 , 7 , 8 , 9 , 1 0}\}$ & \\
\hline
\end{tabular}

2

$4 \quad$ Decision Pages

6 The response forms used in the experiment consist of six decision pages. Each decision

7 page contains one of the following tables, summary instructions for the choice task in the

8 table, and explanation of the lotteries on that page. Full text of the decision pages is

9 available upon request to the authors. The decision pages were given to individual

10 subjects in independently drawn random order. Subjects had access to all six decision

11 pages while making their decisions on every page. One decision page for each subject

12 was independently, randomly selected for money payoff.

13

14

Table Q

\begin{tabular}{|c|c|c|}
\hline Option A & Option B & My Choice \\
\hline$\$ 7$ & $\begin{array}{c}\mathbf{\$ 2 . 5 0} \text { if ball from }\{1\} \\
\text { or } \\
\mathbf{\$ 7 . 5 0} \text { if ball from }\{2,3,4,5,6,7,8,9,10\}\end{array}$ & A $\quad$ B $\quad$ I \\
\hline
\end{tabular}

15

Table S

\begin{tabular}{|c|c|c|}
\hline \multirow{2}{*}{ Option A } & Option B & My Choice \\
\hline \multirow{2}{*}{$\$ 27$} & \$2.50 if ball from $\{\mathbf{1 , 2 , 3 \}}$ & A B I \\
& or & \\
\hline
\end{tabular}


Table U

\begin{tabular}{|c|c|c|}
\hline Option A & Option B & My Choice \\
\hline$\$ 35$ & $\begin{array}{l}\$ 2.50 \text { if ball from }\{1,2,3,4,5\} \\
\text { or } \\
\$ 67.50 \text { if ball from }\{6,7,8,9,10\}\end{array}$ & A $\quad$ B I \\
\hline \multicolumn{3}{|c|}{ Table W } \\
\hline Option A & Option B & My Choice \\
\hline$\$ 31$ & $\begin{array}{l}\$ 2.50 \text { if ball from }\{1,2,3,4,5,6,7\} \\
\text { or } \\
\$ 97.50 \text { if ball from }\{8,9,10\}\end{array}$ & $\begin{array}{lll}\mathbf{A} & \mathbf{B} & \mathbf{I}\end{array}$ \\
\hline
\end{tabular}

7

8

9

Table $\mathbf{R}$

\begin{tabular}{|c|c|c|}
\hline \multirow{2}{*}{ Option A } & Option B & My Choice \\
\hline \multirow{2}{\$22}{} & $\begin{array}{c}\mathbf{\$ 2 . 5 0} \text { if ball from }\{\mathbf{1 , 2 , 3 , 4 , 5 , 6 , 7 , 8}\} \\
\text { or }\end{array}$ & A B I \\
& $\$ 100.00$ if ball from $\{\mathbf{9 , 1 0}\}$ & \\
\hline
\end{tabular}

10

11

Table T

\begin{tabular}{|c|c|c|}
\hline \multirow{2}{*}{ Option A } & Option B & My Choice \\
\hline \multirow{2}{*15}{} & or & A B B I \\
& $\$ \mathbf{1 2 7 . 5 0}$ if ball from $\{\mathbf{1 0}\}$ & \\
\hline
\end{tabular}


Questionnaire (with anonymous, coded responses)

Thank you very much for participating in our decision experiment. We would like to ask you a few questions. Your privacy is protected because your name will not appear on this questionnaire or on your decision tables.

\section{Information about you:}

1. What year are you in school? Freshman ___ Sophomore Junior Senior Grad.

2. What is your intended or declared major?

3. What is your age?

4. What is your gender? Female Male

5. What is your race? Asian _ Black/African American White _ Other Prefer not to respond

6. What is your height? Feet Inches

7. Are you a smoker? Yes No

8. What is your birth order? Oldest child in your family? Youngest child? Middle child?

General Questions: Please answer the following questions on a scale of 1-10, where 1 is Strongly Disagree and 10 is Strongly Agree. Please circle the number that represents your best answer.

1. I seek opportunities for doing things that I never did before.

$$
\begin{array}{cccccccccc}
\mathbf{1} & \mathbf{2} & \mathbf{3} & \mathbf{4} & \mathbf{5} & \mathbf{6} & \mathbf{7} & \mathbf{8} & \mathbf{9} & \mathbf{1 0} \\
& & & & & & & & \\
& \text { Strongly disagree } & & & & & & & \text { Strongly agree }
\end{array}
$$

2. I don't worry about the consequences of what I do. 
1

3. I never get lucky breaks.

$$
\begin{array}{cccccccccc}
1 & 2 & 3 & \mathbf{4} & \mathbf{5} & \mathbf{6} & \mathbf{7} & \mathbf{8} & \mathbf{9} & \mathbf{1 0} \\
& & & & & & & & \\
\multicolumn{3}{l}{\text { Strongly disagree }} & & & & & & & \text { Strongly agree }
\end{array}
$$

4. I frequently get jittery and worry about things.

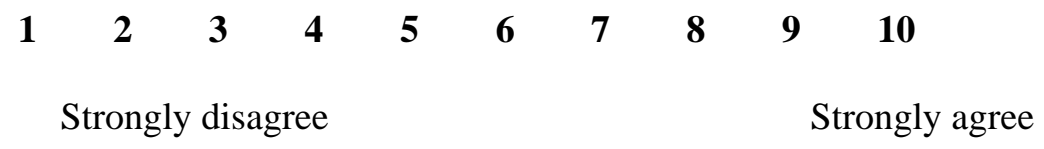

5. I proceed with care in most endeavors.

$\begin{array}{cccccccccc}\mathbf{1} & \mathbf{2} & \mathbf{3} & \mathbf{4} & \mathbf{5} & \mathbf{6} & \mathbf{7} & \mathbf{8} & \mathbf{9} & \mathbf{1 0} \\ & & & & & & & & \\ & & & & \end{array}$

6. I always assess the prospects and risks before starting a new activity.

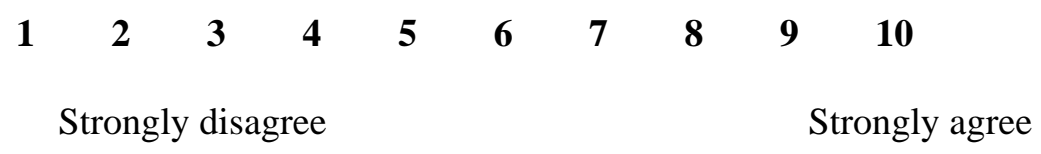

7. I tend to do dangerous things without adequate precautions.
$\begin{array}{llllllllll}1 & 2 & 3 & 4 & 5 & 6 & 7 & 8 & 9 & 10\end{array}$ Strongly disagree
Strongly agree 